\title{
Eye-tracking the semiotic effects of layout on viewing print advertisements
}

\author{
George Damaskinidis, Evangelos Kourdis, Evrpides Zantides \& Eleni Sykioti
}

\begin{abstract}
The print advertisement produces meaning for its readers through the interaction of a complex system of semiotic elements. Understanding this meaning is based on readers' ability to follow the established reading conventions of their culture. The article describes a study that uses eye-tracking technology to examine readers' interaction with the semiotic elements of two print advertisements. The relation between print advertisements and semiotics is informed by intersemiotic analysis and the reading path concept. The advertisements' layout is rearranged to form two sets of texts: one original advertisement and a modified version. We have calculated the time sequence in which visual and verbal areas attract attention, the amount of time spent on them and the depth of attention paid to the areas read. The results show how layout re-arrangement affects reading behaviour, such as reading the smallest visual first and the target text sequentially without visual elements interrupting the reading, or having the same point of entry in both the original and the modified advertisements.
\end{abstract}

Keywords: eye-tracking technology, graphic design, multimodal text, page layout, polysemiotic text, print advertisements, semiotic elements

\section{Introduction}

In print advertisements, there are verbal and non-verbal elements such as images, headlines, logos, fact boxes, typography, page layout, size, placement and colour that interact in various complex ways to produce meaning for the readers. Readers' understanding of this meaning is based on their ability to follow the established reading conventions of their culture. In Western societies, for example, a text's narrative path leads from left to right and from top to bottom. In the design of a print advertisement, breaking these rules may lead to misunderstandings on the part of consumers.

In order to obtain the necessary knowledge about the way consumers approach and understand advertisements, we need to construct models that accurately predict actual visual exposure and advertising impact. Among other things, such a model would need to take into account "the visual saliency of low-level visual features of internet advertisements (e.g. colour, contrast, animation" (Gidlöf, et al, 2012, p. 343). As a follow up to such explorations of the way "graphic and layout properties of advertisements affect the amount of teenagers' visual attention" (ibid. 338-339) on the Internet, we aim to contribute to this line of research by using print advertisements and university students with expertise in graphic design.

In the current study, we use eye-tracking technology to examine the way that specific graphic design parameters can influence, or not, the reading behaviour of readers of specific print advertisements. Eye-tracking studies are a particularly common method in Human Computer Interaction research, and have recently provided interesting data in semiotic research, too. Derboven (2011, p. 3) argues that "semiotic theory can be introduced into an eye-tracking study, augmenting and clarifying the results obtained from the study". This synergy seems to be a semiotic visual advantage, since a structured 
sequence of semantically related elements can help viewers to grasp the main message faster. It has, for example, been claimed that the human visual system extracts and groups similar features and separates dissimilar ones (Palmer, 1999).

According to Henderson and Ferreira (2004, p. 18), "eye movements provide an unobtrusive, sensitive, real-time behavioural index of ongoing visual cognitive processing". Here, we aim to analyse how readers of a magazine advertisement construct their own reading paths and how this reading behaviour changes in two different versions of the same advert. In order to narrow the focus of our research, we have tried to answer a single question: "How do changes in the layout of print advertisements affect the reading behaviour of readers?" For exploratory purposes, the relevant parameters are: semiotic signs that commonly constitute an advertisement (photographs, block of texts, logos and graphics), the expected reading direction (in terms of a Western reading behaviour, from left to right, and from top to bottom), and the outcome of changing the visual and verbal elements of advertisements from the right side of the page to the left side, and from top to bottom. This study aspires to add to the body of evidence reporting effects of layout on reading behaviour (Leckner, 2012).

In what follows, Section 2 provides the relevant theoretical background in advertising and semiotics. Section 3 then introduces the concept of a reading path and the relationship between verbal and non-verbal semiotic systems, within a multimodal framework. Next, in Section 4 we give an overview of the methodological considerations that underlie the empirical aspect of eye-tracker research. Then, in Section 5 we present and discuss the results of the empirical research and we answer the research questions. We conclude with the relevance of this empirical research in the context of advertising and semiotics in Section 6.

\section{Advertising in semiotics}

Semioticians usually view a print advertisement as a polysemiotic text. According to Lotman (2009 [1992], p. 115), "a contemporary semiotics study considers text as one of the basic research concepts, but text itself is considered a functional rather than a stable object with constant properties." The function of the concept of text is related to its definition, since several semioticians identify text with language and, consequently, with one particular semiotic system. The reading of a text as a complex semiotic system consisting of verbal and non-verbal semiotic systems, expressed within a unified space, constitutes a fundamental principle in a semiotic approach to advertising. Tchertov (2015, p. 83) argues that:

\footnotetext{
... in a broad semiotic sense, texts are complex constructions of meaningful units, which are formed and interpreted by definite semiotic systems. Texts in such a broad sense can be regulated not only by a verbal language, but also by non-linguistic and even by non-sign, semiotic systems of signals and indexes.
}

This argument has been put forward by the Tartu-Moscow School, where the concept of language is not used in the usual sense of a natural language in the spoken, signed or written modes, but in the "specifically semiotic sense" (Uspenskij et al. 2003 [1973], p. 297). The broad notion of the concept of language is applied "to any carrier of 
integral (textual) meaning - to a ceremony, a work of the fine arts, or a piece of music" (ibid.). Such a concept is shared by translation scholars who argue that:

\begin{abstract}
... as semiotics implies semantics, any channel of expression in any act of communication carries meaning. For this reason, even exclusively non-verbal communication may deserve the label "text", thus accommodating phenomena as music and graphics, as well as sign language (for the deaf) and messages in Braille (for the blind) (Gottlieb 2003, p. 167).
\end{abstract}

However, such theorising of non-verbal communication as a text does not take into account the concept of space. Van Leeuwen (2005, p. 198) proposes the term "composition" to describe this articulation of semiotic modes in space. In fact, he identifies the concept of composition in space with that of layout (ibid, p. 181). Space and layout, as visual semiotic modes, are core constituent parts of advertisements because they form the "two-dimensional and three-dimensional space, as compared with the onedimensional sequence of verbal language" (Arnheim 1969, p. 232).

Dyer (2009 [1982], p. 91) argues that "the meaning of an advertisement is not something there, statically inside an ad, waiting to be revealed by a correct interpretation." This argument is related to the multiplicity of synergistic semiotic systems found in advertisements. The fact that these advertisements do not deliver onesided meanings is mainly due to the connotations they carry. In semiotics, meaning includes both connotative and denotative aspects (Barthes, 1964). Denotation could be described as the literal, obvious or common-sense meaning of a semiotic sign; for example, in linguistics, the denotative meaning is typically found in a dictionary. On the other hand, the term connotation refers to the socio-cultural and personal associations (ideological, emotional, etc.) of the sign. These associations are typically related to the people who interpret the sign based on their class, age, gender, ethnicity and so on.

These meanings are created through the synergy of semiotic systems, where the text-as-anchorage selects appropriate connotations in the image. The interpretation of images, in addition to the anchored linguistic message, could be enhanced or modified by looking both at their literal or denotative meaning and their symbolic or connotative meaning. The print advertisement, where all the visual and verbal elements are co-present on the paper, is a polysemiotic genre which is suitable for analysing the interplay of verbal and pictorial elements (Torresi, 2008), even though both involve the visual modality. Thus, print advertisements are "a good starting point for studying aspects of visual communication" (Van Leeuwen, 2005, p. 8).

According to Greimas and Courtés (1986, p. 219), the advertisement falls under the category of so-called syncretic semiotics, which refers to the expression and content forms constituted by elements belonging to several heterogeneous semiotic systems. Examples of syncretic semiotics are opera and film, but also natural communication, for they involve gestures, attitudes, speech, etc. Contemporary terms associated with syncretic semiotics are multisemiotic texts and multimodal discourse (O'Halloran, 1999; Kress and Van Leeuwen, 2006). Greimas and Courtés (ibid.) also claim that the majority of the literature on syncretic semiotics focuses on the manipulative aspect of communication. This bilateral aspect of signs has already been highlighted by Barthes (1964) to whom the first semiological analysis of the advertisement has been attributed. 
The advertisement, when approached from the point of view of syncretic semiotics, is both a polysemiotic/multisemiotic text and a multimodal text, in the sense of Kress and Van Leeuwen (2006). It should be noted that these terms are not synonymous, as for example O'Halloran (1999, pp. 317-318) uses the term multisemiotic to describe texts that deploy more than one semiotic resource, and the term multimodal to describe different sensory modalities (e.g. auditory, visual or tactile), a usage that we adopt for clarity in the present article. ${ }^{1}$

\section{Intersemiotic analysis and reading paths}

We use Kress and Van Leeuwen's (2006) term reading path, in the context of reading printed intersemiotic texts, as a metaphor for interpreting the multimodal discourses, design and production of advertisements. A reading path is a notion which relies on the assumption that "all forms of semiosis are read syntagmatically" (O'Halloran 1999, pp. 322-324) against the patterned whole of the text.

Polysemiotic texts function in a non-linear way, in which readers follow their own reading paths to negotiate the various elements on the page. Kress and Van Leeuwen (2006) argue that such types of text impose a paradigmatics on the reader, in contrast to more traditional forms of linear text. In other words, non-linear texts give readers the freedom to select those elements according to a logic of information presented at the centre vs margin, or given vs new information. Therefore, it might be difficult for readers who do not follow the same reading paths to come to a consensus over the reading and interpretation of the same polysemiotic text. In print advertisements, which may be considered as rich polysemiotic texts, advertisers:

\footnotetext{
... usually build up rich and highly structured multimodal frameworks, where redundancy plays an important part as it not only reiterates the message across time and space ... but also ensures that the message gets through to the reader by simultaneously repeating it, or scattering its components, across several co-occurring sensory channels and modes of expression (Toressi 2008, p. 66).
}

Lotman (2005 [1984], p. 206) argues that as regards relationships between semiotic systems, "in reality, clear and functionally mono-semantic systems do not exist in isolation". Therefore, the use of eye-tracking technology to study the reading paths of the semiotic elements that fuse in a polysemiotic text so as to produce intersemiotic meaning has become an important research area.

One of the striking features of eye-tracking technology is related to the fact that it can trace the reader's attention. As Levy-Schoen $(1983$, p. 6) mentions, "to the extent that eye movements are reliable correlates of the sequential centering of attention, we can observe and analyze them in order to understand how thinking goes on". More precisely, "it is considered that the use of eye-tracking becomes relevant in better understanding the reception of visual and auditory stimuli in the information processing of contents"

\footnotetext{
${ }^{1}$ Kress and Van Leeuwen (2001, p. 20), on the other hand, define the concept of multimodality as the "use of several semiotic modes in the design of a semiotic product or event together with the particular way in which these modes are combined." A key feature of this concept is the proliferation of multimodal texts which "are defined as those whose meanings are realized through more than one semiotic code" (Kress and Van Leeuwen 2006, p. 177).
} 
(Mealha et al. 2010, p. 3) For this reason, several studies (see Derboven, 2011; Gidlöf, Holmberg and Sandberg, 2012) that employ eye-tracking technology focus on marketing, and in particular on advertising, whose major aim is to manipulate the public in such a way so as to appear to be informing the public about a product in an unbiased way. Carter et al. (2012, p. 57) also mention that:

\footnotetext{
... eye movement across the page (side to side and top to bottom) is controlled by column rhythms, typographic weights, and rules functioning as visual punctuation. By the manipulation of these elements, the designer groups information according to its role in a given layout and guides the eye methodically through the space of the page.
}

It is common knowledge that readers in Western societies read from left to right However, there are endless combinations in which a visual hierarchy can be created in a page layout or advertisement, and a graphic designer who is well versed in basic typographic and design principles can easily surprise viewers by successfully questioning this anticipated reading habit. Tselentis (cited in Haley 2012, p. 222) refers to a range of factors that can direct the hierarchy of information, as well as eye movement, such as "letterform size, letterform weight, letterform design characteristics, text color, text contrast with the background, text position and orientation on the page or screen, and general mass".

According to Tschichold and McLean (2006, p. 70) "a logical organization of the text is needed, through the use of different type-sizes, weights, placing in relation to space, colour etc." As regards colour, approaching it as a basic unit of visual language (Saint-Martin, 1990) would make it possible to examine ocular fixation and the focus of the gaze, which are key visual variables in eye-tracking research. For Kress and Van Leeuwen $(2001$, p. 21$)$, design is "a particular way of combining semiotic modes". In particular,

[d]esign is still separate from the actual material production of the semiotic product or the actual material articulation of the semiotic event.... The resources on which design draws, the semiotic modes, are still abstract, capable of being realized in different materialities . . . The same design can be realized in different media. (ibid., p. 6)

As suggested by Bertin (1967), the semiotic variables of graphic language, namely location, shape, orientation, colour, texture, value (tone) and size, are also central and applicable to the fundamental design principles of visual hierarchy in general. Similarly to the visual variables introduced by Saint-Martin (1990, p. 17), they cannot be considered independently as basic units of visual language "because at the same time the one is present, the others are manifested".

An interesting related approach has been Machiels and Orth's (2017) visual examination of the contribution of layout to advertisements. Taking the notion of verticality in label positioning as a visual cue on products, they showed that it could change product perception and intention. For example, seemingly trivial design features, such as label positioning and context verticality, were regarded by consumers as inferring power and yielding higher product quality. If vertical product orientation has positive consequences for purchase intent (ibid.), then this awareness in the process of product design and display could help advertisers to better communicate brand characteristics and 
thus increase sales. In addition, Machiels and Orth have highlighted the association of power-related aspects with product size, logo positioning and upward orientation in logos. From another, broader perspective, products have been associated with the abstract concepts of luxury and necessity to relate them to hedonic pleasure and the need to meet more utilitarian goals, respectively (Khan, Dhar and Wertenbroch, 2005). However, these two attributes are not necessarily mutually exclusive for a given product. For example, purchasing a personal computer to play games makes it a hedonic product. On the other hand, buying an expensive graphic card to enhance a computer's performance when playing a particular game makes it utilitarian.

In order to examine empirically the effects of visual layout on reading behaviour, we conducted an experimental study with real participants during a reading activity, using eye-tracking technology. In the next section, we present the methodological considerations as regards the overall research design, the participants, the data-texts, the data collection procedure and the use of an eye-tracker.

\section{Methodological considerations}

\subsection{Research design}

The study was conducted at the Semiotic and Visual Communication Lab of the Department of Multimedia and Graphic Arts, at Cyprus University of Technology in Limassol. We used eye-tracking equipment and retrospective questionnaires to measure undergraduates' visual interaction with two print advertisements (see data-texts A and B in Fig. 1). All experimental sessions took place on the same day and each student had one minute to read each text. The working scenario was that they were passengers on a flight from Cyprus to Greece and they needed to find a restaurant and a hotel. As they were reading the magazine, their eyes fell on advertisements of a restaurant (Data-text A) and a hotel (Data-text B) and they decided to get more information. In order to add a sense of realism to the scenario, during the reading of both texts a typical audio recording of flight instructions was also played.

\subsection{Participants}

The people that took part in the eye-tracking experiments were undergraduates of the Department of Multimedia and Graphic Arts at Cyprus University of Technology in Limassol. The decision to invite these students was based on the practical reason that the eye-tracker is installed in their department's lab. The students (henceforth called participants) were randomly selected, on a voluntary basis and upon availability, and divided into two groups of ten participants each. The choice to use students from a graphic arts department was based on the idea that one of their main jobs is expected to be designing multimodal texts, such as the data-texts under investigation here. The study placed the participants in the position of readers of a print advertisement as well as that of professionals who are called upon to give their expert opinion on a revised version. 
Public Journal of Semiotics 8 (1)

\subsection{Data texts}

Figure 1 shows the two sets of data-text we used with the eye-tracker. They were taken from Blue magazine (Volume 34, 2011), which is distributed to passengers of the Greek airline Aegean. The researchers chose this particular volume on one of their flights from Greece to Cyprus in early 2013.

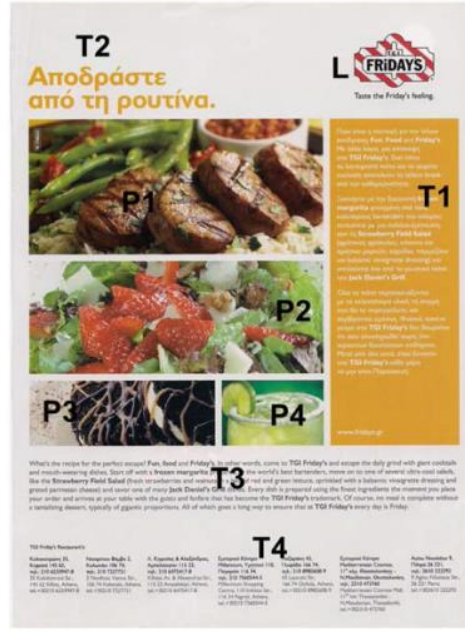

Data-text A

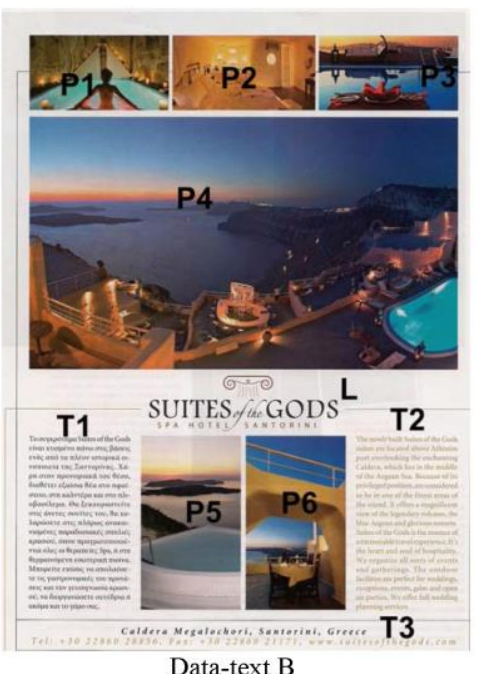

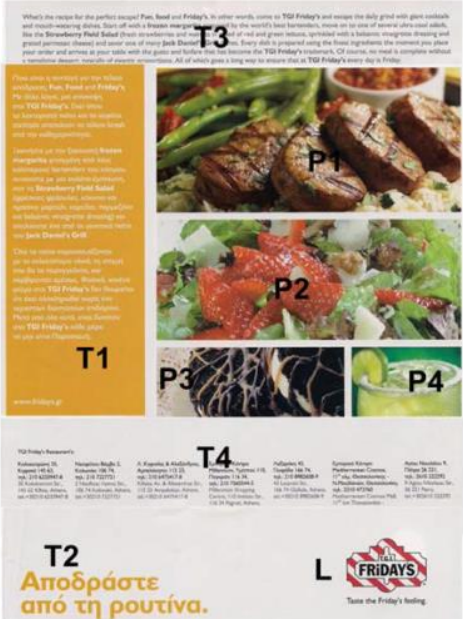

Data-text A1
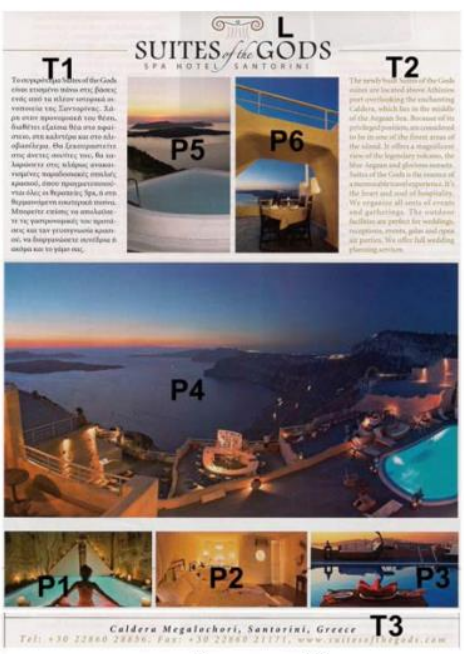

Data-text B1

Figure 1. The original (A and B) and modified (A1 and B1) data-texts used in the experiment

$\mathrm{A}$ and $\mathrm{B}$ are the original data-texts, while $\mathrm{A} 1$ and $\mathrm{B} 1$ are two versions that we modified for the purposes of this research. The modifications were made with a view to changing the standard reading paths in western thinking, from left to right and from top to bottom (Kress and Van Leeuwen, 2006). In Data-text A1, all assigned areas of interest (AOIs) were rearranged, from top to bottom and from right to left, to examine whether 
the participants' reading paths would follow the standard Western mode or if certain semiotic elements could break this rule. In Data-text B1, there was only a top-bottom rearrangement so as to focus on the importance of verticality (Machiels and Orth, 2017) in attracting participants' attention.

This modification was done for the purpose, of testing if changing the layout of the various semiotic elements would have an impact on reading behaviour. Another related exploratory issue was to examine whether changing the position of the largest photograph would change participants' reading paths in the advertisements.

Both texts are full-page advertisements in a typical glossy magazine. All four datatexts were assigned areas of interest (AOIs) and labelled accordingly, where $\mathrm{T}$ (1-4) stands for 'text', P (1-4) stands for 'photo', and L stands for 'logo'. For the purposes of this research, the advertisements were reproduced to be $20 \times 27 \mathrm{~cm}$ in size. In Data-text A, the space each AOI took up in centimetres is as follows: $\mathrm{T} 1=6 \times 15, \mathrm{~T} 2=9 \times 2, \mathrm{~T} 3=2 \times 27$, $\mathrm{T} 4=20 \times 2, \mathrm{P} 1=14 \times 6, \mathrm{P} 2=14 \times 6, \mathrm{P} 3=9 \times 3, \mathrm{P} 4=6 \times 3$, and $\mathrm{L}=4 \times 3$. In Data-text $\mathrm{B}$, the space each AOI took up in centimetres is as follows: $\mathrm{P} 1=5 \times 3, \mathrm{P} 2=5 \times 3, \mathrm{P} 3=5 \times 3, \mathrm{P} 4=17 \times 11$, $\mathrm{P} 5=4 \times 7, \mathrm{P} 6=4 \times 7, \mathrm{~T} 1=4 \times 7, \mathrm{~T} 2=4 \times 7, \mathrm{~L}=8 \times 2, \mathrm{~T} 3=20 \times 1$. Any reference to "W" in the data analysis section stands for white space.

The participants were divided into two main groups: those who read original Datatext $\mathrm{A}$ and modified version $\mathrm{B} 1$, and those who read B and modified version A1. In this way we were able to compare and contrast the different reading paths for the same text after its layout had been modified.

\subsection{Data collection and procedure}

Data collection took place in the eye-tracker laboratory during teaching hours. The eyetracker setup, instructions for the participants and experimental procedure for the main data collection was tested on participants (who did not participate in the main research) in a pilot study that took place two weeks ahead of the data collection period. The main adjustments, based on the outcomes of this pilot study, were a reduction in the time allocated to reading the texts, the re-designation of the areas of interest, and the addition of the audio recording. Given the time restrictions attached to our use of the lab, we had to reduce reading time from five minutes to only two. In methodological terms, while this adjustment speeded up the research process, it reduced the amount of data collected.

The aim of the study was to record the participants' natural reading behaviour. We therefore wanted to create an environment that would resemble a typical reading event in order to increase the reliability of the study. Each experimental session consisted of two parts: the eye-tracking recording and the retrospective questionnaire that took place in the classroom next to the lab.

Each participant was welcomed into the room where the recording took place and asked to sit in front of the computer. Once the participant was seated, one of the researchers briefly described the purpose of the experiment and encouraged the participant to ask procedural questions. The chair and the computer were adjusted each time so that the participant would be comfortable. Given the brevity of the time allocated for reading and to allow for a fast change from one data-text to another, the participant was not left alone in the room. Instead, the researcher stood at the back of the lab and kept track of the time, without intervening in the process. Besides, the reading was not 
supposed to take place in isolation (e.g. in a person's living room) but in the presence of other imagined passengers on a flight from Cyprus to Greece.

After the recording was completed, the participant was taken to the nearby classroom to complete the questionnaire without any time restrictions. The questions aimed to estimate the consistency of the reading activity. Although the participants were not obliged to further describe their experience, some of them commented on the experiment.

\subsection{Recording of eye-tracking data}

The eye-tracker employed in the study was a scientific-grade eye-tracker system (SMI RED250mobile). It is a non-intrusive system, placed below the area in need of eyetracking (here, a 22-inch monitor) to detect the participants' eye movements without the need for glasses or other equipment. This eye-tracker allows for binocular tracking, but also has monocular tracking capabilities to increase track time and reduce no capture time. It has an optimal operating distance of $60-80 \mathrm{~cm}$, enables freedom of head movement at about $40 \mathrm{~cm}$ and has an accuracy of 0.4 degrees. Sampling rate is set at 60 $\mathrm{Hz}$ and allows for a 12-point calibration. The data analysis took place using the software BeGaze (SMI software), which allows for standard real time playback and tracking, gaze plots, areas of interest and heat map calculations that are exported later as raw data to a spreadsheet.

\subsection{Post-recording questionnaire}

The use of eye-tracking technology, as a methodological tool, may not be sufficient to yield scientific data for the investigation of a phenomenon (Gidlöf, et al. 2012). In order to assess the participants' readings of the advertisements, we gave them a short questionnaire to be completed immediately after the recording sessions. We used openended (albeit specific) questions about the strategies they adopted, as a way of allowing them to describe their reading experience freely. The purpose of this questionnaire was to reconstruct the recordings in a way that would make the participants recall the process, their choices and the decision-making involved in their reading experiences. Although we included a question related to the two versions of the text (English and Greek), we did not analyse them cross-linguistically, since we were simply interested in examining the way they were "viewed" by the participants, by way of analogy to the other areas of interest. Another important goal was to explore the reasons why they paid attention to certain visual and verbal elements and not to others. Also, it was an opportunity for them to offer their own expertise and thus assume responsibility for their own learning. Table 1 shows the questions asked. 
Table 1. Retrospective questionnaire given to participants

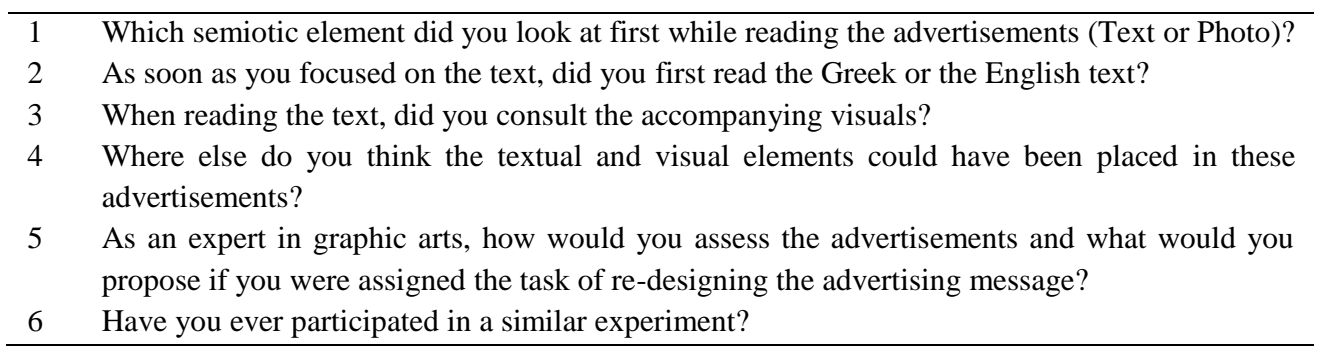

Since the participants were to be selected from the department that owned the eyetracker equipment, we felt it was important to have question 6 for methodological reasons. That is, those who had already participated in an eye-tracking-based experiment might be tempted to consciously or unconsciously modify their standard reading paths as a response to this experience. On the other hand, participants without similar experience might have felt uncomfortable sitting in front of a computer while knowing that their eyemovements were recorded. Although it was not our intention to have a control and experimental group, any distinct deviation in the reading behaviours between the two types of participants would have had to be taken into account during the data analysis.

\subsection{Method of eye-tracking analysis and coding}

The eye-tracking data were analysed with the software BeGaze from SMI. In order to analyse the amount and type of verbal and non-verbal semiotic elements that the participants looked at, the advertisements first had to be identified as areas of interest (AOIs) and coded into semiotic categories of text (columns of verbal language), photo (the products for sale) and logo (the advertised company) (for a relevant discussion see Sections 2 and 3). AOIs were chosen based on their position to the left, right, top, or bottom of the page. In both advertisements, the semiotic elements are placed symmetrically, in a kind of grid form, which seems to invite the reader to read them sequentially. For example, there is no text or photo that intrudes upon or overlaps another. The statistics of the compiled eye-movement data were then exported from BeGaze into a database for further analysis.

Identified semiotic elements were coded into one of three categories: text (T), photo $(\mathrm{P})$ and logo (L). A number was added to each text and photo to allow comparisons between the participants. In each advertisement, the sequence (that is, the order in which the participants gazed at the AOIs) for each semiotic element was identified as follows. When a semiotic element was read either first, second or third, it was designated as the participants' first choice; when it was read either fourth, fifth or sixth (and seventh for advertisement B), it was designated as his/her second choice; and when it was read either eighth, ninth or tenth, it was identified as the participant's third choice. 


\section{Data analysis and discussion}

\subsection{Data analysis}

The change in layout of the AOIs led to variations in the sequence in which the participants read them. Figure 2 shows the different sequences for both sets of data-texts. The extreme cases L (1) and W-P1 (9-10) retained their positions, with a slight tendency towards lower positions. On the other hand, the largest variations appear in T4 and P2, which fell from the $2^{\text {nd }}$ and $3^{\text {rd }}$ positions to $6^{\text {th }}$ and last place, respectively. Also, P4 and $\mathrm{T} 2$ ascended from the $5^{\text {th }}$ and $8^{\text {th }}$ positions to the $1^{\text {st }}$ and $2^{\text {nd }}$, respectively.

\begin{tabular}{|c|c|c|c|c|c|c|c|c|c|c|c|c|}
\hline & & \multicolumn{10}{|c|}{ Sequence } & \\
\hline \multirow{5}{*}{ Data-texts } & \multirow{2}{*}{$\mathbf{A}$} & $1^{s t}$ & $2^{\text {nd }}$ & $3^{\text {rd }}$ & $4^{\text {th }}$ & $5^{\text {th }}$ & $6^{\text {th }}$ & $7^{\text {th }}$ & $8^{\text {th }}$ & $9^{\text {th }}$ & $10^{\text {th }}$ & \\
\hline & & $L$ & $T 4$ & $P 2$ & $T 1$ & $P 4$ & P3 & T3 & $T 2$ & $W$ & $P 1$ & \\
\hline & & & & & & & & & & & & \\
\hline & & $1^{s t}$ & $2^{\text {nd }}$ & $3^{\text {rd }}$ & $4^{\text {th }}$ & $5^{\text {th }}$ & $6^{\text {th }}$ & $7^{\text {th }}$ & $8^{\text {th }}$ & $9^{\text {th }}$ & $10^{\text {th }}$ & \\
\hline & A1 & $P 4$ & $T 2$ & $L$ & $T 1$ & $T 3$ & T4 & $P 3$ & $P 1$ & $W$ & $P 2$ & \\
\hline & & & & & & & Sequ & & & & & \\
\hline & & $1^{s t}$ & $2^{\text {nd }}$ & $3^{\text {rd }}$ & $4^{\text {th }}$ & $5^{\text {th }}$ & $6^{\text {th }}$ & $7^{\text {th }}$ & $8^{\text {th }}$ & $9^{\text {th }}$ & $10^{\text {th }}$ & $11^{\text {th }}$ \\
\hline & B & $P 4$ & $W$ & $L$ & $P 5$ & $P 1$ & P6 & P3 & $P 2$ & $T 3$ & $T 1$ & $T 2$ \\
\hline Data-texts & & & & & & & & & & & & \\
\hline & & $1^{s t}$ & $2^{\text {nd }}$ & $3^{\text {rd }}$ & $4^{\text {th }}$ & $5^{\text {th }}$ & $6^{\text {th }}$ & $7^{\text {th }}$ & $8^{\text {th }}$ & $9^{\text {th }}$ & $10^{\text {th }}$ & $11^{\text {th }}$ \\
\hline & B1 & $\mathrm{P} 4$ & $\mathrm{~L}$ & $\mathrm{P} 5$ & T3 & $\mathrm{T} 1$ & W & P6 & $\mathrm{P} 2$ & $\mathrm{~T} 2$ & P3 & $\mathrm{P} 1$ \\
\hline
\end{tabular}

Figure 2. Average sequence of fixations for Areas Of Interest (AOIs) in Data-texts

While in Data-text A the AOI "T2 and L" (the payoff line) were not read sequentially (or at least within a small amount of time), in Data-text A1 they were read in this way. Although P4 has the smallest size, it was read first in A1. In both data-texts, the last AOI was a large photograph and in A1 it was added to the second largest photograph. In Data-text A, the Greek verbal (T1) was separated from its English translation (T3) by two visuals (P4, P3), but in Data-text A1 they were read sequentially. Out of 10 AOIs, two retained their position $(\mathrm{T} 1, \mathrm{~W})$, one moved down one place (P3), three moved two places (L [down], P1 [up], T3 [up]), and four moved more than three places.

In data-texts B and B1, the first element viewed was $\mathrm{P} 4$, which was the largest in size. While in Data-text B L was the participants' third choice, in Data-text B1 it moved up one place. Moreover, three verbal elements (T1, T2, T3) were in the last position in Data-text B, but moved up to the highest middle positions in B1. In general, other than P4 and $\mathrm{L}$, which remained the participants' first choice in both data-texts, the remaining elements had widely varying positions in B and B1. Also, while in Data-text B all verbal semiotic elements were read only after the non-verbal elements were viewed, in B1 the verbal and non-verbal elements were viewed in a random alternate mode (e.g. visualverbal-visual-verbal).

By changing the layout in Data-text B, all photographs became the participants' second choice. In both data-texts, B and B1, the photograph that attracted participants' 
attention was P6 (that is, not the largest photo). Moreover, the placement of $\mathrm{L}$ at the top in Data-text B moved it down to the last viewing position.

Table 2. Average fixations on verbal and non-verbal elements

\begin{tabular}{llccc}
\hline & & \multicolumn{3}{c}{ Fixations (\%) } \\
\hline \multirow{5}{*}{ Data-texts } & A & Text & Photo & Other non-verbal \\
& A1 & 42 & 37 & 21 \\
Data-texts & B & 32 & 35 & 18 \\
& B1 & 15 & 53 & 15 \\
& & & 59 & 26 \\
\hline
\end{tabular}

As shown in Table 2, while the time spent on reading non-verbal AOIs in datatexts A and A1 was almost the same, in Data-text B1 it was reduced (almost) to half. As regards the photographs and other non-verbal elements, again, the changes in Data-text $\mathrm{B}$ had a higher impact on the time spent viewing them.

Table 3. First fixations on verbal and non-verbal elements

\begin{tabular}{llccc}
\hline & \multicolumn{4}{c}{ Fixations } \\
\hline & & Text & Photo & Other non-verbal \\
Data-texts & A & 3 & 2 & 5 \\
& A1 & 3 & 2 & 5 \\
Data-texts & B & 3 & 4 & 3 \\
& B1 & 2 & 6 & 2 \\
\hline
\end{tabular}

Table 3 shows that, in general, the participants' point of entry remained the same in the modified versions of data-texts A and B. Also, no particular AOI dominates, although there is a preference for the other non-verbal elements. Perhaps the most noticeable point is that while L garnered a bit of attention in Data-text B, in Data-text B1 it attracted the least attention when it was the first element seen by participants (see also Figure 2).

Figure 3 shows four heat maps, one for each data-text. The heat map refers to the fixation times (average time that a user fixates on the area of interest) using a colour scale from blue (least) to red (most). In Data-text A, most of the fixation was in the upper left hand corner of P1 and T2, and in the upper half of T1. Its modified text, A1, had most of the fixation on $\mathrm{T} 1$. Also, the fixation times on $\mathrm{L}$ were slightly longer in A1 compared to A. In Data-text B, T1 and P4 received considerable fixation, but these received much less fixation in Data-text B1. As regards the verbal elements in B1, while T2 had a dramatic rise in fixation time, T1 lost most of its fixation. Moreover, in Data-text B1, P4 managed to maintain some fixation, although this was focused at the bottom left hand corner, compared to the central focus in Data-text B. 


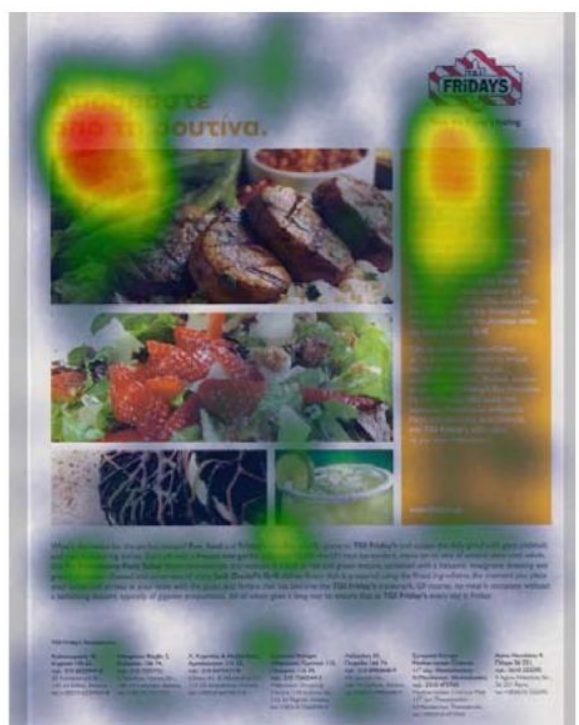

Heated data-text A

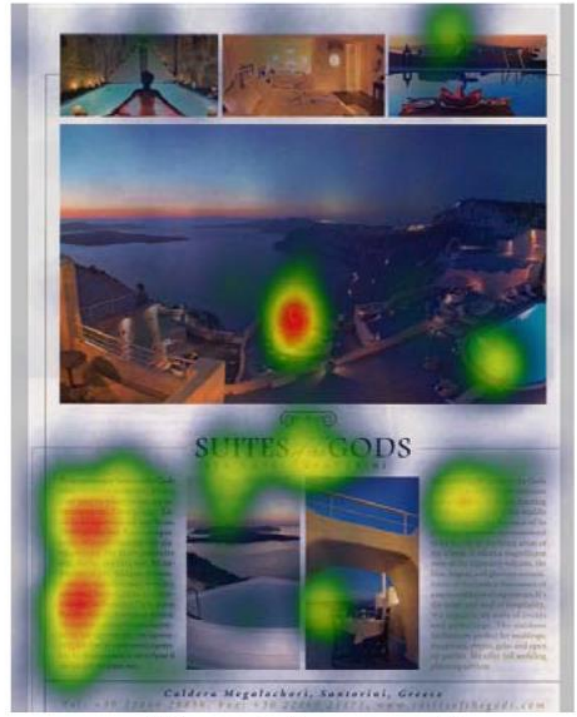

Heated data-text B

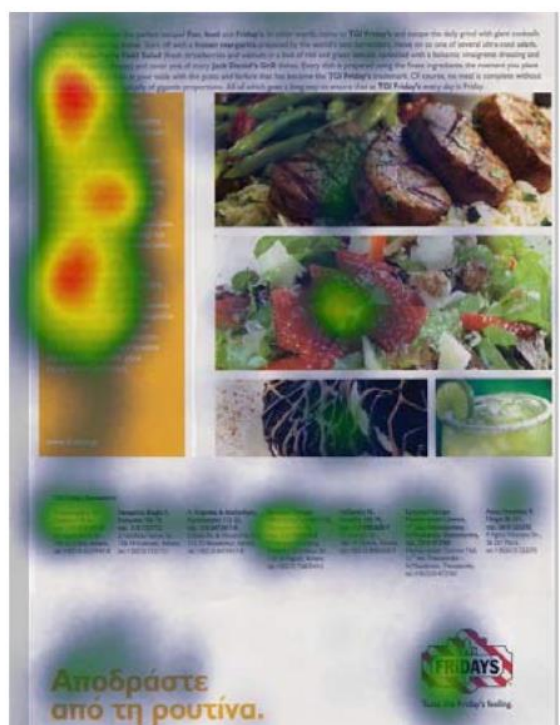

Heated data-text A1

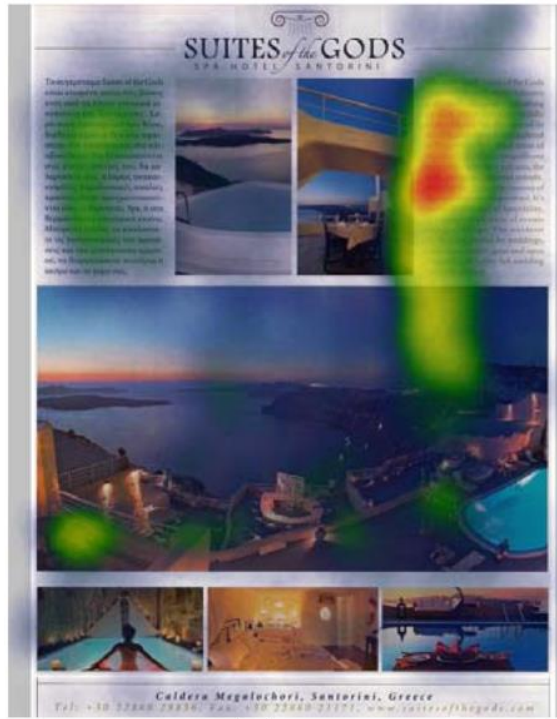

Heated data-text B1

Figure 3. Heat maps for data-texts A, A1, B and B1

In Figure $4 \mathrm{a}$ and Figure $4 \mathrm{~b}$ we can see eight still frames of a video that shows the scan path of data-texts A and A1. These frames were extracted every fifteen seconds and were placed next to each other. The first fifteen seconds in the modified Data-text A1 present evidence that the visuals have attracted more attention from this reader than they did from the reader of Data-text A. While the yellow AOI has been moved to the left, or 'before the reading area' of the data-text, the time spent on reading has been slightly reduced. In addition, we can see an increase in cross-readings between the logo AOI and 
the bottom-text area. In the next fifteen seconds, the yellow AOI in Data-text A1 has significantly attracted the reader's attention, and the same applies for the logo AOI in relation to the bottom text AOI. In the second half of the video, while the tendency to focus on the yellow AOI and the photos continues, the focus on the logo AOI remains unaltered. At the end of the video, there is a noticeable overall increase in the attention span and focus on the yellow AOI and the photographs.

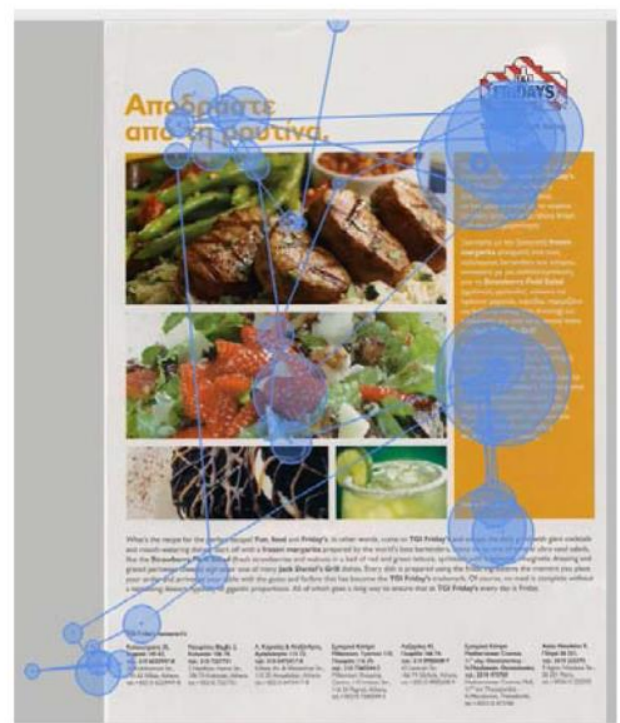

Data-text A 00:00-00:15

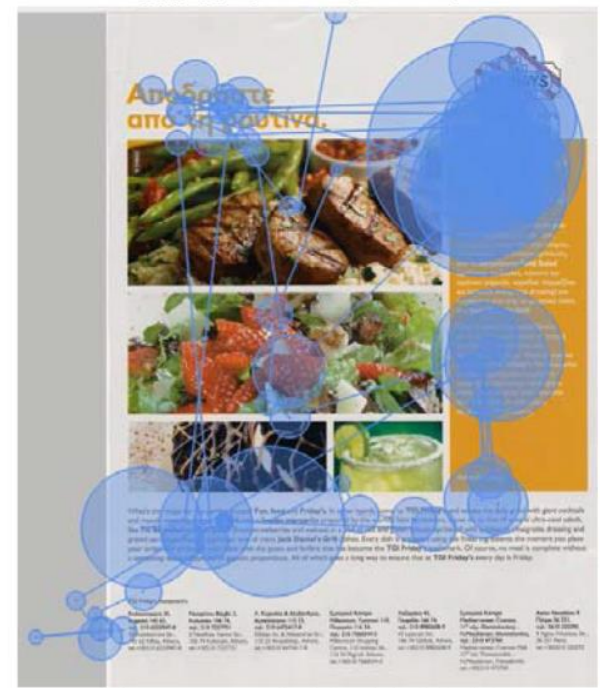

Data-text A 00:16-00:30

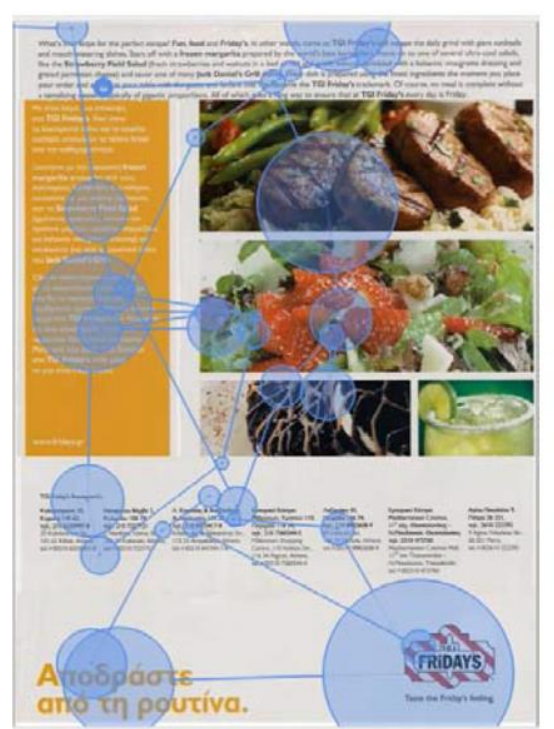

Data-text A1 00:00-00:15

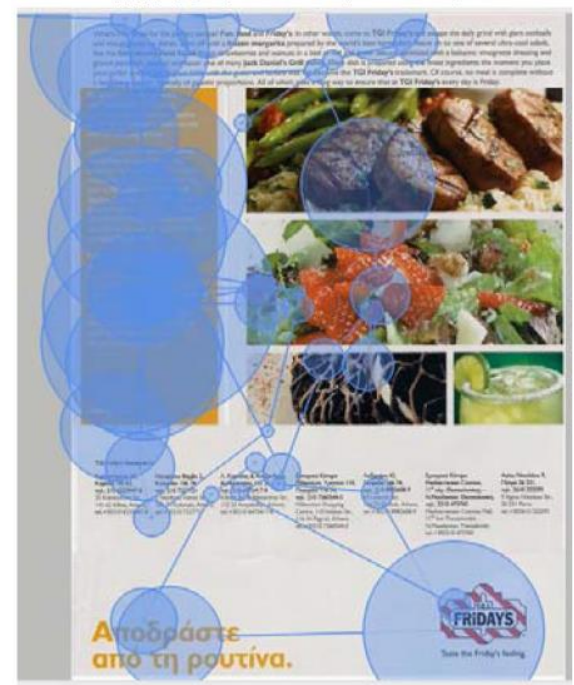

Data-text A1 00:16-00:30

Figure 4a. Still frames of a scan path video for data-texts A and A1 every fifteen seconds 


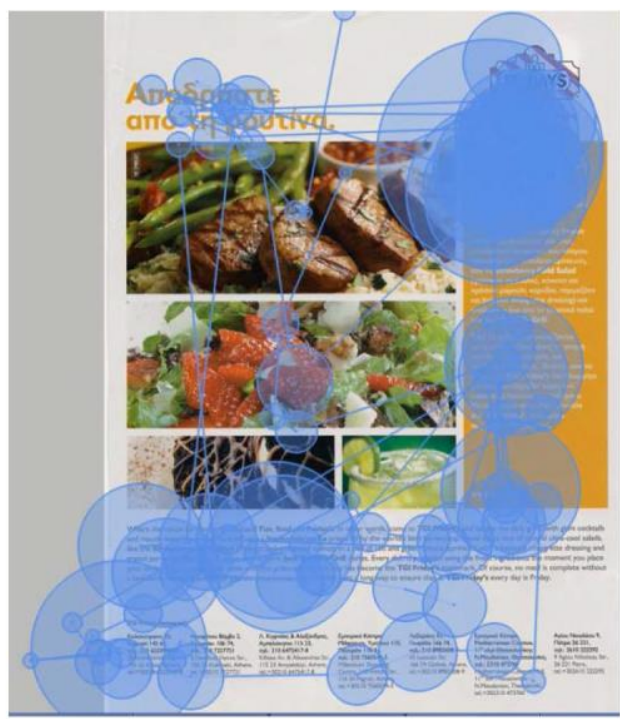

Data-text A 00:31-00:45

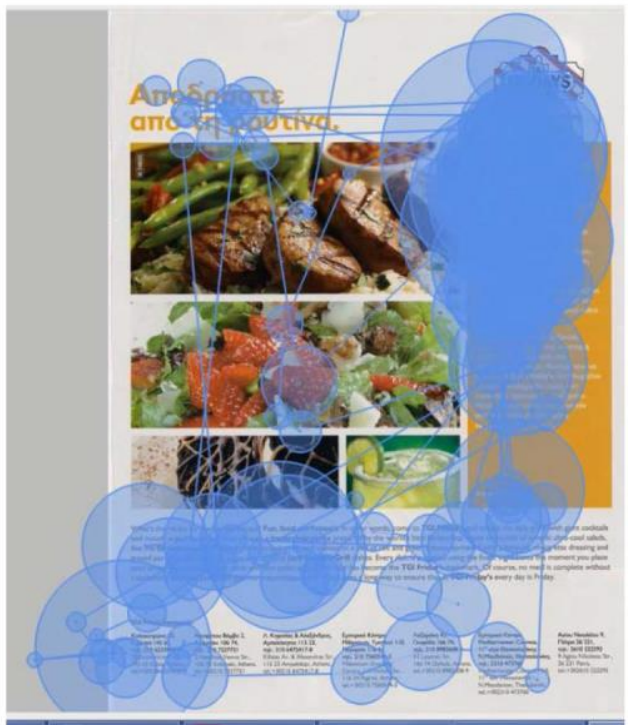

Data-text A 00:46-01:00

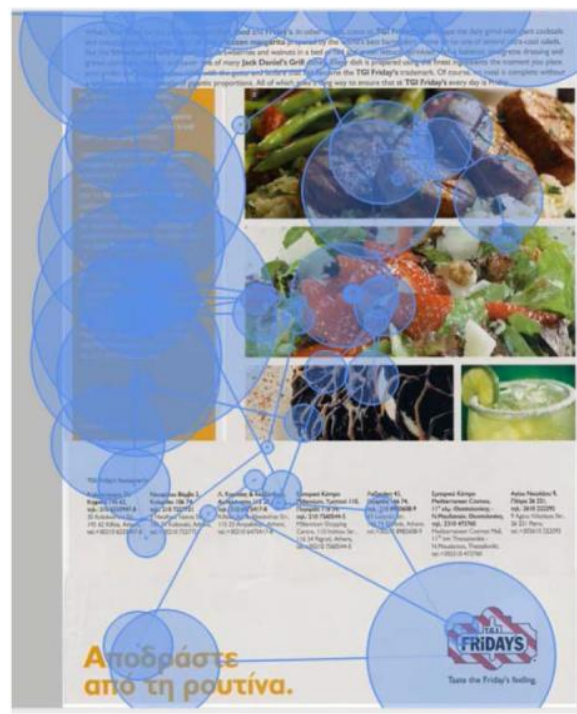

Data-text A1 00:31-00:45

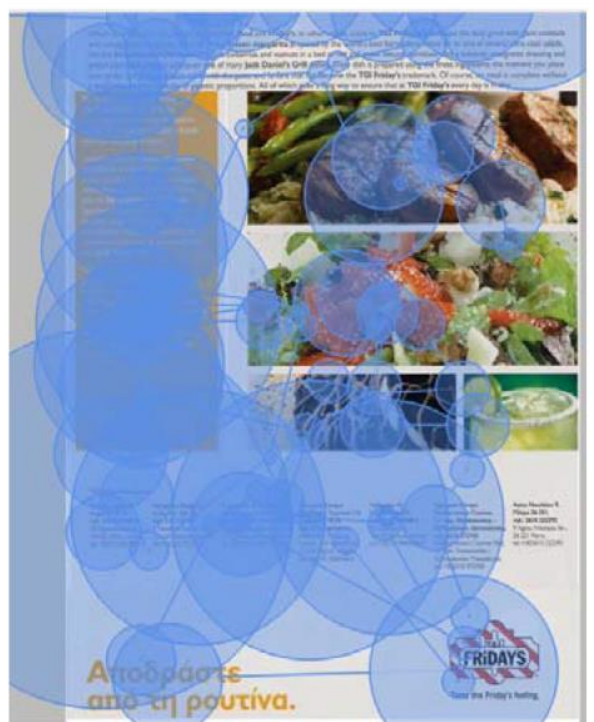

Data-text A1 00:46-01:00

Figure 4b. Still frames of a scan path video every fifteen seconds

According to Table 4, participants' answers to the retrospective questionnaire do not show great variations between the two groups. The semiotic element that mostly drew participants' attention was the photos, with the text coming second, while a combined reading of both text and photo was very limited. It is not surprising that the Greek text drew by far the most attention. Almost all participants declared that they read the text with close reference to the accompanying visuals. All participants proposed exactly the 
same modifications if they were to redesign the advertisement (different font, bigger letters, semiotic elements in hierarchical order), without however elaborating on the exact nature of their choices. A feature that differentiates the two groups of participants is the fact that while in group A-B1 almost all the participants had previously participated in a similar experiment with eye-tracking technology, in group B-A1 almost half of them had not. It is likely that the formation of the groups could have contributed to differences, but this cannot be corroborated unless more empirical data are collected with these two types of participants. To verify this likelihood, we would have to follow up with an experimental study involving the particular group B-A1 and another group where half of the participants would not have participated in a similar experiment.

Table 4. Participants' answers to the retrospective questionnaire

\begin{tabular}{|c|c|c|c|}
\hline \multicolumn{4}{|c|}{ Reading pairs } \\
\hline \multirow{7}{*}{ 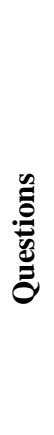 } & & A-B1 & B-A1 \\
\hline & 1 & Text: 2; Photo: 7; Text and Photo 1: & Text: 3; Photo: 5; Text and Photo 2: \\
\hline & 2 & GR: 7; EN: 1; GR and EN: 2 & GR: 8; EN: 2; GR and EN: 2 \\
\hline & 3 & Yes: 8; No: 2 & Yes: 9; No: 1 \\
\hline & 4 & $\begin{array}{l}\text { Summary: Centre-Top-Bottom-Side, for } \\
\text { both verbal and visuals. }\end{array}$ & $\begin{array}{l}\text { Summary: Centre-Top-Bottom-Side, for } \\
\text { both verbal and visuals. }\end{array}$ \\
\hline & 5 & $\begin{array}{l}\text { Summary: different font, bigger letters, } \\
\text { semiotic elements in hierarchical order }\end{array}$ & $\begin{array}{l}\text { Summary: different font, bigger letters, } \\
\text { semiotic elements in hierarchical order }\end{array}$ \\
\hline & 6 & Yes: 9; No: 1 & Yes: 6; No: 4 \\
\hline
\end{tabular}

\subsection{Discussion}

The distinctive feature of these advertisements is the extensive use of visual semiotic elements, and in particular, photographs. The purpose of this research was not to examine the verbal content, namely a Greek text and its English translation, but rather to test the effect of different spatial arrangements of the semiotic elements on visual attention. Eyetracking technology was used to examine the way participants viewed the two advertisements, including a modified version of each one of them with a different layout of the visual and verbal semiotic elements.

The change in the layout of both texts affected participant behaviour in various ways. Some of these changes led to variations in the sequence in which the participants read the revised advertisements. While it could have been expected that the largest photographs in both data-texts would attract readers' attention first, this was not the case. The change in the data-texts' layout led some participants to read the smallest photograph first and the largest one last. Thus, the point of entry for viewing these multisemiotic texts is a non-verbal element, no matter its size or position on the page. Consequently, despite the manipulations of data-texts A1 and B1, it seems that both add the effect of making viewers read the visual elements first. 
The different layout also forced the participants to read the Greek text and its English translation sequentially without any visual element interrupting the reading. On the other hand, the different layout in one data-text made the participants spend more time on reading the verbal elements. However, since the two texts were examined as an integrated visual space, rather than a text for reading, it could not be verified if this reading involved also viewing the relevant visual elements. It is worth highlighting the fact that the (large) size of an image and its (central) position on the page (see Fig. 3, BB1) may not secure viewers' unimpeded attention when the surrounding semiotic elements change positions.

The participants' answers to the retrospective questionnaire confirm, to an extent, the data-based analysis, but participants would need to be interviewed in order for us to draw more definite conclusions from this retrospective analysis. The participants acknowledged that the semiotic elements that captured their attention at the beginning of their viewing were non-verbal and they regularly visited them during the reading of the verbal elements. Also, the attempt to increase the study's ecological validity by using an auditory announcement might have introduced an uncontrolled variable into our study, which may have impacted eye-movement behaviour.

The participants' proposals, as regards the redesigning of the advertisement, are identical for both advertisements. This unanimity could be ascribed to the fact that the participants are undergraduates of the same university department and have therefore been taught in a particular way. However, they do not explain what they mean by "arranging the semiotic elements in hierarchical order", nor do they describe or justify their statements (e.g. type of fonts, size of letters).

\section{Conclusion}

The theoretical focus of this study was the differential spatial arrangement of visual semiotic elements in advertising. The experimental data verified the argument that space, and in particular layout, is a constituent part of reading behaviour, attracting the attention of readers to various degrees (Tchertov, 2015). The synergy of the same semiotic elements arranged in different ways creates multiple patterns of meaning-making. This multiplicity of meaning makes distinguishing a print advertisement as a polysemiotic text a difficult task (Kress and Van Leeuwen, 2006). For that reason, it is necessary to have more experimental studies with various sub-typologies of advertisements.

Eye-tracking technology was used to address this theoretical question experimentally. In particular, the goal of this experimental study was to examine the effect of layout on the reading behaviour of university students, using two print magazine advertisements. Similarly to previous studies (see Leckner, 2012; Mealha, et al, 2010), eye-tracking technology has been invaluable in giving experimentally-based insights into reading behaviour.

Additionally, advancing previous studies, our findings highlight the non-linearity of polysemiotic texts and the paradigmatics they impose on readers to follow their own reading paths (Toressi, 2008). This finding may have implications for the design of the same print advertisement in different modes (e.g. for multilingual audiences), media (e.g. for digital versions) or formats (e.g. to maintain column rhythm), to guide the eye through the space of the page (Carter, 2012). 
An implication for the designers of advertisements is the need to pay attention to potential image-text interactions because verbal reading and visual viewing may not be sequential but intermingled. A promising line of future research, in the context of training graphic design students, is to use eye-tracking experimental studies to assess students' ability to design advertisements that could direct readers' attention when reading polysemiotic texts. Participants' suggestions for improving the design of the advertisements underline how seemingly irrelevant cues (e.g. changes in typography) can aid advertisement designers to better communicate the advertised products, since such a factor could direct the hierarchy of information (Tselentis cited in Harley, 2012).

The main research limitations of this study have to do with the inherent limitations of eye-tracker technology, the modification of the data-texts and the selection of the participants. First of all, cognitive processes cannot be directly inferred from eye-tracking data. Another typical characteristic of eye-tracker research is the overabundance of data, which makes data collection and analysis quite difficult and time-consuming. Furthermore, although the researchers have received basic training in eye-tracking technology, eye-tracking research requires thorough training before one can be expected to collect valid and reliable data. One way to mitigate this limitation is the use of methodological triangulation (e.g. retrospective questionnaire and different data for the same reading habit).

The modification of the data-texts was dictated by our exploratory intention to examine left-right and top-bottom reading behaviour and only for specific visual and verbal parts. In this way, strictly speaking, the modified data-texts are not the advertisements originally designed by the advertisers, but are in fact new ones (albeit similar to the original advertisements). Thus, from a methodological perspective, it could be argued that two pairs of two different advertisements were examined. While the datatexts are published in a print medium (a magazine), they were scanned so that they could be imported into a computer for digital reading. However, reading on a screen is quite different from reading a printed page. Additionally, bearing in mind that the pages were isolated from their immediate context (the magazine itself), the experimental procedure did not take into account actual browsing through a magazine.

The participants were randomly selected and their individual reading habits and other demographic details (e.g. age, sex, educational background) were not recorded. As students of a graphic design department, they may have been sensitive to the design of the advertisements. Coupled with the fact that they were aware of taking part in an experimental procedure, their reading behaviour may have been influenced somehow.

Overall, the findings contribute to an increased knowledge of the role of design in print advertisements, and it extends our understanding of how non-verbal semiotic elements can be used to direct consumers' gaze.

\section{Acknowledgments}

This study is based on research that has been financed by the Research Committee of Aristotle University of Thessaloniki (AUTH). Research funding project "The use of eyetracking in exploring the effect of semiotic resources on reading Greek-English advertisements". Research project code: AUTH 91398. We would also like to thank the Semiotic and Visual Communication Lab of the Department of Multimedia and Graphic 
Arts of Cyprus University of Technology for granting us use of the eye-tracker system. Also, many thanks to all the students for their voluntary participation and friendly cooperation. Finally, we would like to thank the anonymous reviewers and the editor for their insightful comments on an earlier draft version of this article.

\section{References}

Arnheim, R. (1969). Visual thinking. Berkeley \& Los Angeles: University of California Press.

Barthes, R. (1964). La rhétorique de l'image. Communications, 4, 40-51.

BeGaze (SMI software). Sensomotoric instruments analysis software. Available from: https://www.smivision.com/eye-tracking/software-downloads/

Bertin, J. (1967). Semiology of graphics: Diagrams, networks, maps. Madison, WI: The University of Wisconsin Press.

Carter, R., Day, B. \& Meggs, P. (2012). Typographic design: Form and communication. New Jersey: John Wiley \& Sons.

Derboven, J. (2011). One plus one equals three: Eye-tracking and semiotics as complementary methods in HCI. In Second international symposium on culture, creativity and interaction design - BCS HCI 2011. Available from: https://lirias.kuleuven.be/bitstream/123456789/324093/1/one-plus-one-equalsthree_derboven.pdf.

Dyer, G. (2009 [1982]). Advertising as communication. Abingdon \& New York: Routledge.

Gidlöf, K., Holmberg, N. \& Sandberg, H. (2012). The use of eye-tracking and retrospective interviews to study teenagers' exposure to online advertising. Visual Communication, 11, 329-345.

Gottlieb, H. (2003). Parameters of translation. Perspectives: Studies in Translatology 11(3), 167-187.

Greimas, A-J \& Courtés, J. (1986). Sémiotique. Dictionnaire raisonné de la théorie du langage II (Compléments, débats, propositions). Paris: Hachette.

Haley, A. (2012). Typography, referenced: A comprehensive visual guide to the language, history, and practice of typography. Beverly, MA: Rockport Publishers.

Hederson, J.-M. \& Ferreira, F. (2004). Scene perception for psycholinguists. In J.-M. Hederson \& F. Ferreira (Eds.), The integration of language, vision, and action: Eye movements and the visual world (pp. 1-58). New York: Psychology Press.

Khan, U., Dhar, R. \& Wertenbroch, K. (2005). A behavioral decision theory perspective on hedonic and utilitarian choice. In: Ratneshwar, S. \& Mick, D.G. (Eds.), Inside consumption: Frontiers of research on consumer motives, goals, and desires (pp. 144-165). New York: Routledge.

Kress, G. \& Van Leeuwen, T. (2001). Multimodal discourse. London: Arnold.

Kress, G. \& Van Leeuwen, T. (2006). Reading images. The grammar of visual design (2nd edn). London: Routledge.

Leckner, S. (2012). Presentation factors affecting reading behaviour in readers of newspaper media: an eye-tracking perspective. Visual Communication, 11, 163184.

Lotman, Y. (2005 [1984]). On semiosphere. Sign Systems Studies, 33(1), 205-229. 
Lotman, Y. (2009 [1992]). Culture and explosion. Berlin: Walter de Gruyter.

Levy-Schoen, A. (1983). Central and peripheral processing. In R. Groner, C. Menz, D. F. Fisher, and R. A. Monty (Eds.), Eye movements and psychological junctions: international views (pp. 65-71). Hillsdale, NJ: Lawrence Erlbaum Associates.

Machiels, C. J. A. \& Orth. U. R. (2017). Verticality in product labels and shelves as a metaphorical cue to quality. Journal of Retailing and Consumer Services, 37, 195203.

Mealha, O., A. Veloso, S. Almeida, R. Rodrigues, L. Roque, R. Marques \& C. Manteigueiro (2010). Eye tracking data and visualisation: On information and communication studies at CETAC.MEDIA. Journal of Eyetracking, Visual Cognition and Emotion, 1(1), 1-10.

O'Halloran, K. L. (1999). Interdependence, interaction and metaphor in multisemiotic texts. Social Semiotics 9(3), 317-354.

Palmer, S. E. (1999). Vision science: Photons to phenomenology. Cambridge, MA: MIT Press.

Saint-Martin, F. (1990). Semiotics of visual language. Bloomington: Indiana University Press.

SMI RED250mobile. Sensomotoric Instruments eye tracker system. Available from: https://www.smivision.com/eye-tracking.

Tchertov, L. (2015). On spatial modelling. Sign Systems Studies, 43(1), 77-101.

Torresi, I. (2008). Advertising: A case for intersemiotic translation. Meta LIII(1), 62-75.

Torresi, I. (2009). Advertising. In M. Baker \& G. Saldanha (Eds.), Routledge encyclopedia of translation studies (pp. 6-10). London \& New York: Routledge.

Tschichold, J. \& McLean, R. (2006). The new typography: A handbook for modern designers. Berkeley: University Of California Press.

Uspenskij, B., Ivanov, V., Toporov, V., Pjatigorskij, A. \& Lotman, J. (2003 [1973]). Theses on the semiotic study of cultures (as applied to Slavic texts). In M. Gottdiener, K. Boklund-Lagopoulou, and A.-P. Lagopoulos (Eds.), Semiotics, volume I (pp. 293-316). London \& New Delhi: Sage.

Van Leeuwen, T. (2005). Introducing social semiotics. Abingdon \& New York: Routledge.

About the authors, addresses

George Damaskinidis (corresponding author) is Research Fellow at the Laboratory of Semiotics (SemioLab) at Aristotle University of Thessaloniki. His research interests focus on visual literacy, intersemiotic translation, multimodal semiotics and research methodology. He supervises master theses in the Faculty of Education at European University of Cyprus. He is the author of Joint Military English. A specialized language course (2008), by Tourikis Publishing, Athens and the

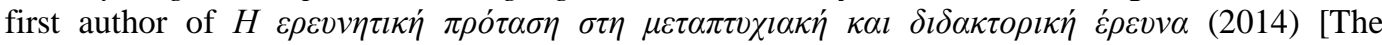
research proposal in postgraduate and doctoral research], published by Epikentro, Thessaloniki.

Laboratory of Semiotics (SemioLab)

Faculty of Philosophy

Aristotle University of Thessaloniki, Greece

damaskinidis@hotmail.com 
Evangelos Kourdis is Associate Professor in the Department of Translation, of the School of French Language \& Literature, Aristotle University of Thessaloniki, Greece. His scientific interests are mainly concentrated in the field of Sociosemiotics, Translation Semiotics, Sociolinguistics, Language Ideology and Cultural Communication. $\mathrm{He}$ is the national representative for Greece to the International Association for Semiotic Studies, vice president of the Hellenic Semiotics Society and an international collaborator at the Semiotics and Visual Communication Laboratory of Cyprus University of Technology.

Department of Translation

School of French Language and Literature

Faculty of Philosophy

Aristotle University of Thessaloniki, Greece

ekourdis@frl.auth.gr

Evripides Zantides is Associate Professor in the Department of Multimedia and Graphic Arts of Cyprus University of Technology in Cyprus. His research interests focus on Semiotics and Identity in the process of audio/visualizing verbal language using image, text/typography and sound. He has participated, with distinguished work, in refereed Art and Design Biennales and other international exhibitions. Actively involved in conference and exhibition committees, he is the delegate for Cyprus to ATypI, the International Typographic Association as well as for IASS-AIS, the International Association for Semiotic Studies. He is also the founder and director of the Semiotics and Visual Communication Lab in Cyprus University of Technology (www.svclab.com).

Department of Multimedia and Graphic Arts Cyprus University of Technology, Cyprus evripides.zantides@cut.ac.cy

Eleni Sykioti is a teacher of Business Administration in the Hellenic Secondary Education. She holds a Master of Business Administration from the Technological Educational Institute of Central Macedonia and a Master Degree in Cultural Studies: Semiotic Structures and Practices from the University of Western Macedonia. Her research interests are mainly in the field of Semiotics of Advertising, Semiotics of Business Administration Course Books, and Attitudes on Teaching Business Administration in Educational Environments with the Use of New Technologies.

elesyk1@yahoo.gr 